Reseñas 


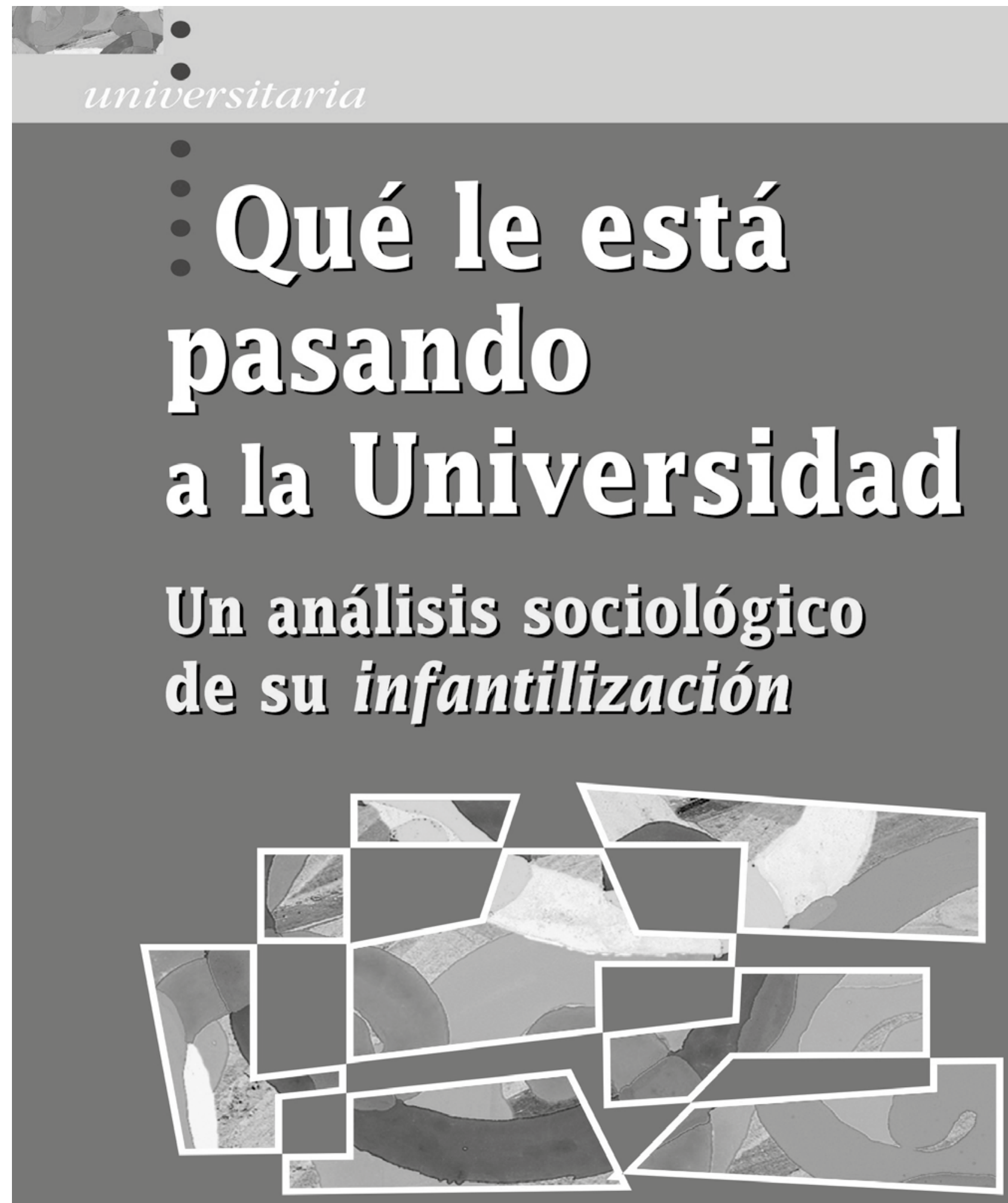

Frank FURED」 


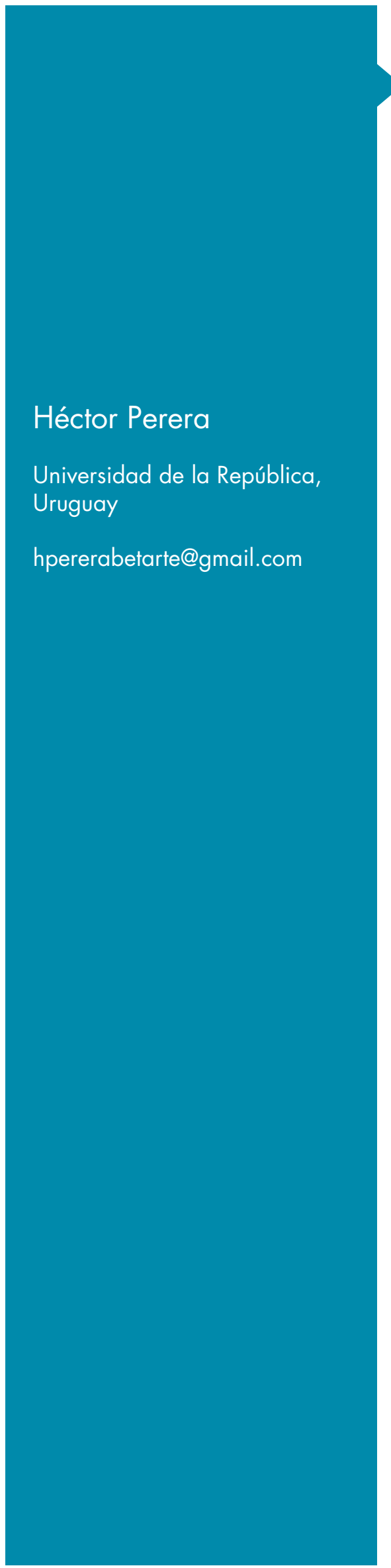

\section{Qué le está pasando a la universidad. Un análisis sociológico de su infantilización}

Autor: Frank Furedi (2018)

El libro que reseñamos fue publicado por la editorial Narcea en la ciudad de Madrid y refiere a la transformación radical que están pasando las universidades en la época actual. La problemática analizada está centrada en las universidades anglosajonas.

Profesor emérito de Sociología en la University of Kent Canterbury, Inglaterra, es autor de una profusa bibliografía sobre temas de la sociología y además es comentarista social. Desde la década de los 90 ha escrito sobre las sociedades occidentales en situaciones de riesgo y de incertidumbre. También sobre la salud, la educación, las nuevas tecnologías y la cultura. Su compromiso es con una educación humanista, y considera que la educación superior debe brindar un lugar adecuado para la experimentación intelectual, la libertad de expresión y la libertad académica, valores que defiende con vehemencia.

Aunque la libertad académica y la libertad de expresión en teoría, aun hoy, se afirmen, en la práctica parecen haber perdido su vitalidad y relevancia para muchos de quienes habitan la universidad. A veces parece que el clima cultural que predomina en la educación superior sea bastante menos hospitalario para los ideales de libertad, tolerancia y debate que el mundo que está tras las puertas de la universidad. Reflexionar sobre cómo se ha producido esta inversión de roles es el principal objetivo de este libro. (p. 8)

El texto está compuesto de un prefacio, una introducción y nueve capítulos, y culmina con una extensa bibliografía en inglés. El propósito manifiesto por el autor es explicar cómo y por qué la cultura que domina la educación superior ha cambiado de forma radical y dramática en los últimos tiempos. «En un asombroso giro de los acontecimientos, la universidad se ha convertido en sujeto del imperativo de las prácticas de censura y culturales que exigen niveles de conformismo que normalmente se asocian con instituciones autoritarias de mentalidad cerrada. Las directrices de la universidad insisten en que sus miembros "midan sus palabras" y sometan su comportamiento a una variedad siempre creciente de reglas. Los miembros de la universidad no son solo simplemente exhortados a hablar con sensibilidad, sino que, en muchos casos, se espera que asistan a clases de formación en sensibilización» (p. 9).

Como consecuencia directa de los procesos de socialización que imperan en la sociedad, se ha producido un cambio radical que ha transformado la universidad posibilitando la extensión de prácticas de censura y prácticas culturales que expresan fuertes niveles de conformismo, asociado a un paternalismo creciente y a un autoritarismo con predominio de una mentalidad cerrada. Las normativas imperantes hacen que las reglas establecidas sometan a los sujetos a situaciones radicalmente opuestas a la libertad de pensamiento. Esto provoca, según el autor, que el cuerpo estudiantil haya «interiorizado profundamente el sistema de valores censor que florece dentro de la academia» (p. 9). 


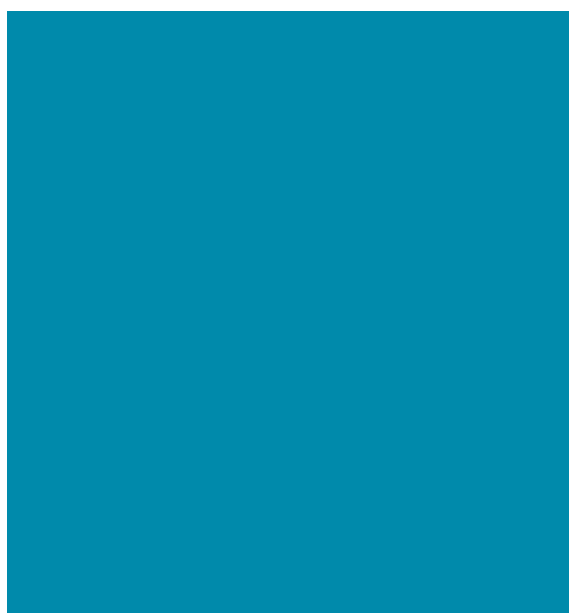

Héctor Perera

Universidad de la República, Uruguay

hpererabetarte@gmail.com
Su planteo está vertebrado por la constatación de que la forma en que los estudiantes han sido educados y socializados influye en esa situación a través de sus actitudes y comportamiento cuando ingresan a la universidad. Todo el planteo, incluidas las prácticas y situaciones descritas en el libro, está exclusivamente referido a las universidades angloamericanas. El problema que denomina «infantilización» en las universidades se inicia en Estados Unidos y se extiende a todas las universidades angloparlantes. De una manera más tenue, esta tendencia se observa también en las universidades de Europa occidental.

Las universidades de los años 60 impulsaban un radicalismo liberal, en ellas se defendía la libertad de expresión y se consideraba inaceptable cualquier forma de censura. Se respetaba la libertad de cátedra. En contraste con esta situación, hoy predominan ideas y acciones que tienen que ver con la protección del estudiante frente a movimientos contestatarios.

En ese sentido gran parte del texto está dedicado a las formas de socialización de las generaciones que ingresan a las universidades y cómo esos modelos imperantes condicionan el comportamiento propenso a la exigencia de protección y al sometimiento sin discusión a las regulaciones que predominan en los centros universitarios. Impera la teoría del retorno al in loco parentis, que conduce a la constatación de una de las novedades más significativas del acontecer universitario: la infantilización.

Transcribe de su texto llamado La cultura del miedo, publicado en 1997, lo siguiente: "Hubo una época en que los estudiantes que se presentaban candidatos para un curso universitario nunca hubieran soñado con ir con sus padres a la universidad para ser entrevistados. En las décadas de 1960 y 1970 , la mayor parte de los estudiantes asociaban ir a la universidad con la idea de alejarse de sus padres. Muchos se habrían sentido avergonzados e incómodos al ser vistos en compañía de adultos por el campus. Durante la pasada década, ha tenido lugar un importante cambio. Los estudiantes ahora llegan al campus para la entrevista junto a sus padres» (p. 19).

Acompañar a los futuros estudiantes a las universidades es visto como un acto de crianza saludable, dado que los estudiantes no se consideran jóvenes adultos con independencia intelectual y moral. Frente a esto, las estrategias de las instituciones universitarias han sido ofrecer protección y ayuda.

Aparecen entonces varios factores que contribuyen a este proteccionismo, tales como la socialización de la generación joven que provoca en los ámbitos universitarios lo que Furedi llama la deificación de la seguridad, convertir cada centro en un espacio seguro, y esto supone apoyar el bienestar de los estudiantes: «... buscan no solo brindar unos mejores servicios terapéuticos sino también alterar el sistema de valores de la enseñanza y regular el ejercicio de la libertad de expresión y de cátedra» (p. 25); la reivindicación de la propia identidad casi como una forma terapéutica frente a las complejidades, dificultades y desafíos que ofrece la vida académica porque supone el cuidado de los estudiantes y la politización de la identidad. «Esa es la razón por la que las demandas en pro de las advertencias de contenido o los espacios seguros para proteger a los estudiantes del daño emocional con frecuencia van unidas a llamamientos a favor del reconocimiento y la validación de la identidad cultural de quienes reclaman esto» (p. 25). La censura es la consecuencia de validar las diversas identidades que se dan en el seno de las universidades; los motores de las políticas paternalistas, lo que equivale decir su orientación paternalista por medio de la reivindicación de la doctrina de in loco parentis que impregna la orientación de la educación superior en los países anglosajones.

Defender la libertad de cátedra y la libertad de expresión es una causa importante por derecho propio. Pero hay otra cuestión fundamental en juego. La socialización de los jóvenes por medio de una narrativa medicalizada que 


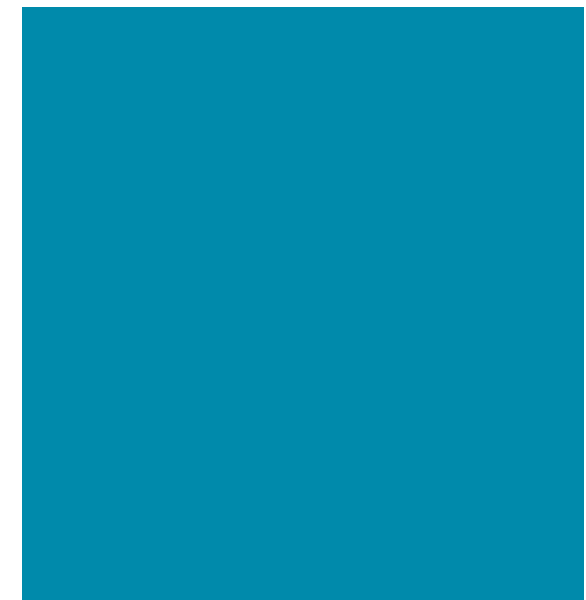

Héctor Perera

Universidad de la República, Uruguay

hpererabetarte@gmail.com de manera sesgada subraya su fragilidad y vulnerabilidad, debe cuestionarse. Los estudiantes necesitan de universidades que les formen para una vida de libertad e independencia, no de espacios seguros que les conviertan en unos infantilizados lloricas que exigen protección. (p. 29)

Los temas resaltados y otros tales como los que se consignan a continuación son analizados minuciosamente y con sorprendentes descripciones de testimonios y experiencias en las universidades anglosajonas. En los nueve capítulos que configuran el texto son destacables también otros temas sobre los cuales Furedi construye su teoría acerca de la infantilización de la enseñanza superior:

La patologización de la libertad de expresión y la censura como terapia semántica.

La teoría de la microagresión y la hipervigilancia sobre las formas y el pensamiento.

El conflicto cultural sobre los valores fundamentales y la libertad académica en una cultura paternalista.

En síntesis: «Las universidades tienen que reeducarse a ellas mismas, y reapropiarse de la libertad académica como los cimientos de su trabajo. No hay mejor lugar por el que empezar que alterar la relación de la universidad con sus estudiantes. El paradigma del estudiante vulnerable debe ser desplazado por uno que presume que los estudiantes son jóvenes adultos que poseen la capacidad de acoger oportunidades y crear un nuevo mundo. Esa es otra forma de decir que debemos tomarnos en serio a los estudiantes y esperar de ellos que sean capaces de actuar como adultos que poseen la capacidad de autonomía moral y el aprendizaje independiente» (p. 216).

Este libro ofrece algunas respuestas al panorama muy complejo que se da hoy en los contextos universitarios norteamericanos, ingleses y europeos. ¿Por qué la cultura universitaria está atravesando estas transformaciones tan dramáticas y preocupantes? Furedi va a la raíz de los problemas que explican gran parte de los acontecimientos que describe minuciosamente y que deberían constituir la principal preocupación de las universidades. Se trata de una lectura imprescindible para entender esta problemática que ha llamado la «infantilización» de las universidades y es seguro que no dejará indiferente al lector interesado en estos temas. La pregunta explícita del título conduce al autor a explicar y dar respuestas a este fenómeno cuyo abordaje se realiza desde una perspectiva sociológica y política.

El libro se encuentra disponible en la Biblioteca de la Comisión Sectorial de Enseñanza de la Udelar. 